\title{
Infantry Fire Tactics
}

Brevet Major W. D. Bird D.S.O., p.s.C., A.A.G.

To cite this article: Brevet Major W. D. Bird D.S.O., p.s.C., A.A.G. (1905) Infantry Fire Tactics, Royal United Services Institution. Journal, 49:332, 1175-1182, DOI: $\underline{10.1080 / 03071840509416623}$

To link to this article: http://dx.doi.org/10.1080/03071840509416623

曲 Published online: 11 Sep 2009.

Submit your article to this journal $\pi$

Џ Article views: 8

Q View related articles $\sqsubset$ 


\title{
INFANTRY FIRE TACTICS.
}

\author{
By Brevet Major W. D. BIRD, D.S.O., p.s.c., A.A.G., Indian \\ Staff College.
}

NOT the least difficult task of a writer who aspires to deal with the large and complex problems of Infantry Fire Tactics within the scope of a brief article, is to discover a satisfactory definition of the term. The words themselves are familiar enough in military jargon, but what is their exact meaning? Tactics we know are the manouvres on the battle-field whereby a general seeks to gain the victory. What, then, are Fire Tactics? Not fire manouvres, as their designation seems to imply, but the principal factor in tactics-the principal means whereby the defeat of the enemy is to be accomplished. " Shooting," in fact, in the words of an American writer, "is to tactics what marching is to strategy."

As there can be no effective fire without sound tactics, so tactics cannot be successful without efficient fire, for with the exception of the final assault, every manœuvre, every movement, undertaken by Infautry. in war, has but one aim and object, viz., Fire Action.

Except to state that the main object is to produce the greatest effect at the earliest moment and in the shortest time, no definite rules can be laid down in regard to Infantry Fire Tastics. War is an art, not an exact science, and the exigencies of the moment decide what is best to do. All that can be attempted is to state the pros and cons of certain courses of action.

The application of the principles of Fire Tactics is like that of the principles of Tactics, merely the application of common sense, in this case, to the direction of fire. This is easily said, but not by any means so easily put into practice. It is proposed therefore to enumerate the more important of these principles in relation to Infantry Fire--which after all decides battles, for it is said to be responsible for 75 per cent. of the casualties-and to illustrate their application by examples from military history.

In all actions the questions to be solved in respect of Fire Tactics are: When is fire to bo opened? What volume is to be employed? And how long is the fire to be maintained?

The first question will be dealt with later in this article. The third depends on the results produced; for instance, it will be useless to continue firing when it is obvious that the fire is not effective. But on the other hand, the occasion of even a temporary mastery of the enemy's fire should be seized by the assailant to press forward, whilst the defender who has retained fire superiority during the musketry fight at decisive range will probably deliver a counterattack.

Regarding the second, the volume of fire to be employed is mainly dependent on the number of men available, the object to be achieved, the quantity of ammunition at hand, the frontage available for deployment, the size and rango of the target, the intensity of the enemy's fire.

For instance, a great volume of fire by a weak forco will decoive the enemy as to its strength, or a feeble fire by a large body of troops 
may induce the enemy to accept battle. Great volume generally means great rapidity of fire, and this is not possible when ammunition is scarce. A favourable target demands that advantage should be taken of the opportunity offered, and ammunition freely expended. The longer the range, the greater must be the volume of fire, for the chances of hitting are obviously less than at short distance.

The last factor is the intensity of the enemy's fire. This involves the question of fire superiority, and to gain fire superiority is the aim and ibject of all Fire Tactics, except when fire is used for purposes of delay or deception. Consequently, if the problem: How to attain Fire superiority, is solved, the more difficult portion of the problem of Infantry Fire Tactics will have been elucidated.

In endeavouring to give a satisfactory reply to the question: How is superiority of Infantry Fire to be attained? one is forced to deal mainly with generalities, for since circumstances alter cases, so in each campaign, nay, in each action, fire superiority is attained by many different means. It is not possible to deal with every combination of circumstances, and therefore only the attainment of fire superiority in a great battle where frontage is limited will be considered.

Fire superiority may be defined as the condition when one sido causes a greater percentage of loss amongst the hostile troops than it suffers itself; that is to say, when its offensive power is in excess of its vulnerability. The superiority may, therefore, be temporary or permanent.

In principle there is but one way of ensuring that the enemy's percentage of loss is heavier, viz., by diminishing the effect of his fire. Many subsidiary factors are, however, involved in this principle, and these it is proposed to consider in detail.

Formerly, Infantry formations were devised so as to ensure the maximum of shock as well as fire power. In present conditions shock action cannot, in ordinary circumstances, be applied until fire superiority has been attained, consequently formations are governed by the latter exigency.

Now, in so far as formations are concerned, since it is apparent that, given equal accuracy, the effect of the enemy's fire may be reduced by subjecting his troops to a fire of greater intensity than that which they are delivering, and since the more rifles that can be brought on the hostile line the greater will be the volume of fire, it would appear that to satisfy this condition the firing line should consist of as many ranks of men, one behind another, as can conveuiently handle their rifles. But such a formation would, owing to the vulnerable target it offers to hostile fire, defeat its own purpose.

Again, to diminish the effect of hostile fire, troops should, as regards formations, be extended to very wide intervals; but in this order the results obtained by their fire would, at decisive ranges, be negligible.

Consequently, a compromise, which appears to combine the advantages of each system; has, at any rate in theory, been adopted in our Service, and it is ordained that a firing line, of a maximum density of one rifle per yard of frontage, is to be established and maintained by the assailant within decisive range of the enemy's position.

In defence, the density of the firing line is held to depend on the field of fire and cover available, but the volume and accuracy of fire must exceed that of the assailant. 
To the soundness of the principle of the dense line, the results of experiments carried out by each successive class of officers at Hythe bear evidence.

On equal frontages are set up lines of small iron-plate falling targets, 1 foot square, at 1 yard interval, and at 7 yards interval, in the proportion of 6 to 1 . A number of officers corresponding to the dense line is drawn up 400 or 500 yards from the targets representing the extended line, and vice versat. Fire is opened simultaneously by both parties, and as a target falls the corresponding man of the other party withdraws. Notwithstanding that the extended line is represented by the best shots of the class, it is invariably annililated in less than one minute.

The experiment is then repeated with firers in the proportion of 3 to 1 and 2 to 1 , and the result is always the easy victory of the dense line. A higher percentage of hits to rounds fired is often obtained by the extended line; but the experiment proves that this is no advantage, for the extended line will require more frequent reinforcement. In similar trials at 900 yards range, however, the results are reversed, thus showing that the fire power of the dense line is at this distance less than its vulnerability, and that our system of attack is sound.

The question, whether the assailant should advance in a dense or extended line, is freely debated in the current military literature of the Continent. It is argued in favour of dense lines that they exercise a good moral effect on soldiers, that they are easily controlled, possess great fire power, and great offensive power; moreover, the moral effect on the adversary of seeing a dense line advancing upon him is likely to be considerable. On the other hand, it is pointed out that dense lines are vulnerable, that the moral effect of losses will be great, that they are subject to panics, if defeated fall into disorder, and that the men will be unable to make the best use of cover.

In favour of open lines it is said that casualties will not be noticed, that they are not prone to panic, that best use can be made of cover, that their vulnerability is small, and that a retirement is but a phase of the scope of their action. But against them it is urged that men are left to their own resources and exposed to severo mental strain, that control is difficult, fire power small, and a succession of extended lines are liable to be beaten in detail.

Without entering into further detail, it may, it is suggested, bo accepted that, other things being equal, the compromise between the two systems will give the best results, for the Hythe experiments show that the dense line will, at decisive ranges, defeat the extended line, when the lateral space occupied by each is identical; but that at longer distances extended lines seem to possess greater fire power in comparison to their vulnerability, whilst undoubtedly the men can in this formation make better use of cover.

There still remains the question, how the required density of fring line is to be attained and maintained.

When the enemy is well trained, it is held, in our Army, that in ordinary circumstances ground cannot at long or effective ranges be gained in action unless, on the one hand, the hostile line is subjected to a continuous fire, and the accuracy of the enemy's fire thereby diminished, and on the other, the target offered by tho assailant is reduced to the smallest possible dimensious by mens of widely extended formations. 
Continuous fire can only be combined with movement. when from first to last the movement of one unit, be it a body of troops or single soldier, is covered by the fire action of another unit. Thus, when the attack is first launched, the advance should be covered by artillery fire, and by the long-range Infantry fire of troops specially detailed. When effective range is reached, ground should be gained under this covering fire, assisted by tho mutually supporting action of the firing line; and, finally, reinforcements should advance, covered by the fire of the men established in the fire position.

The important factor in war is the enemy's fire. Troops not themselves under fire will shoot with telling effect; but as soon as they are exposed to effective fire, their shooting falls off, they take hurried aim, or do not aim at all, and think more of saving their own lives than of taking those of their opponents. Hence the value of covering fire, the employment of which, combined with judicious use of ground, alone makes a successful attack possiblo against a well-armed and trained opponent.

Instances of the employment of covering fire are numerous in modern war. A good example is the advance of the fusiliers of the 74th Regiment against the Rotherberg at Spicheren, as is the recapture of the outskirts of Le Bourget during the siege of Paris by the Germans. Another is Skobeleff's attack on the Turkish positions at Sheinovo; a third is Majuba; another, the capture of San Juan Hill, near Santiago, Cuba, by the Americans. The retirement may also be quoted of the British and Americans after the unsuccessful attempt to capture Tientsin in 1900; and lastly, the capture of the Gyantse jong in Tibet.

Under the protection of this fire, ground will, it is believed, usually be gained in action by the successive advance of lines of widely extended skirmishers, the leading men of which establish themselves as near to the enemy's line as possible, and are reinforced until the necessary density of firing line is attained.

In special cases, however, it may be desirable to deploy a dense firing line from the commencement of the action, e.g., when surprise is inflicted, in a close country, or when the enemy's position can bo approached under cover.

Before further considering the question of fire superiority, it may be remarked that modern firearms seem to have modified the relative advantages of the offensive and defensive in the following manner:-

1. The defensive now, as ever, possesses the advantages of choice of position, concealment, facilities for ammunition supply, and knowledge of range.

2. The offensive, as before, can select the point of attack-a great gain in these days of extended lines of battle, and claims certain moral advantages. But, in addition, the long range and containing power of modern rifles confer a power of concealing mancuvre by fire action, and of concentration of fire, which was not previously held. On the other hand, it is universally agreed that modern firearms have greatly enhanced the price which must be paid for tactical mistakes by the assailant.

Now the range at which fire is opened exercises a considerable influence on the eventual attainment of superiority. In the decisive attack, it is generally lield that since supply of ammunition must be precarious, and fire can only produce a decisive effect at close 
range, and since it is to the interest of the assailant to procure an early decision, and long-range fire will produce delays, the fire of the executive troops should be reserved until close range is reached; but at the same time should not be withheld so long that the losses suffered by the assailant will bring about his defeat before he has commenced to fight.

On the other hand, fire should be opened from even extreme range on a favourable target.

The defensive attitude implies inferiority, and since it is to the interest of the defender to restore the balance of equality, fire action may as a rule be commenced as. soon as effect will be produced, and even at longer ranges if it is desired to tempt the assailant to commit himself. In cases, however, where surprise is possible, or the ground near the defender's line is very favourable to fire effect, or when the defender possesses marked superiority in fire power or moral, fire may be reserved, and victory sought rather from the rapidity of loading than the ranging power of the rifle.

These views do not, however, meet with universal approval. In favour of the normal use of long-range fire it is argued that the ranging power of the rifle should be utilised; that fire of this nature, owing to the curve of the trajectory, searches trenches; that in favourable circumstances it is very effective; that its moral effect is great; that concentration is easy; the enemy's line can more easily be enfiladed at long range; that long range covering fire is effective; that long-range fire is useful to make the enemy show his hand, to hold him to his position, to deceive him; and that it is advantageous in siege warfare. But, on the other, it is urged that long-range fire delays attack; it involves large expenditure of ammunition; it is trying to eyes and nerves; if ineffective it encourages enemy; the difficulty of ascertaining range is prohibitive to its employment; and the effect of long-range fire is dependent on observation of fire. Moreover, it is said that decisive results are only obtained at short ranges, and as concentration of fire is essential, troops using long-range fire must necessarily be in close and therefore vulnerable formations.

Whether these views are justified or the reverse, it is, however, certain that long-range fire necessitates, as has been stated, concentration, and large expenditure of ammunition, and though collective fire is likely to be effective whenever the target is clearly visible, it would appear that its size must decide whether the expenditure of ammunition likely to be involved to secure adequate results will bo justified or not.

Generally speaking, except in special circumstances, the teaching of military history is adverse to the employment of long-range fire by the assailant, and no single instance can be quoted where, except against savages, it has produced a decisive success.

On the other hand, in the war of 1877, the Russians found that when troops opened fire at long range it was a sure sign that the attack had failed. In the Serbo-Bulgarian War of 1885 , at the battle of Slivnitza, the Servian left wing abandoned the attack because it. had expended all its ammunition at long range. And in 1891, in the Chilian Civil War, the Congressional troops in one action fired from 150-200 rounds a man in three-quarters of an hour in indecisive contest at long range. The Chinese acted in a similąr manner at Hai-cheng in the Chino.Japanese War, 
In defence, however, where ranges will be known and supply of ammunition comparatively easy, fire may, as already suggested, usually be opened at long range, but must be discontinued if it fails to produce the desired result, as it is trying to the nerves and eyes, and failure to check the enemy will react unfavourably on the moral of the defender. Still, even when employed by the defender, longrange fire has never produced decisive results against trained troops. The nearest approach is the loss inflicted on the Prussian Guard at St. Privat in 1870; but nevertheless, these troops are said to have struggled on to within 600 yards range of the village. The Turks in 1877 were great exponents of long-range fire; badly trained troops ustually are, but though they delayed the Russians, the latter were always able to come to close quarters. A typical instance occurred during the attack of Kourloff's column on the Turkish positions near Sofia, where the Russians lost 1 General and 200 men in the skirmish line at 2,000 yards rauge. The Turks were, however, driven off after four hours' fight, when the Russians reached a point about 500 yards from the position.

It must nevertheless be remembered that fire to deceive or contain an opponent is generally delivered at long range.

Reserved fire-the converse to long-range fire-may be defined as fire withheld until the opposing forces come within decisive range of one another, i.e., within the distance at which a soldier may reasonably expect to hit an individual of the opposing force at whom he aims.

The greatest military authorities have, since, and even before, the introduction of arms of precision, favoured the principle that fire should be reserved until decisive range is reached. At Fontenoy, under Count de Saxe, the French emnloyed these tactics. Wellington's Generals also frequently reserved fire. Stonowall Jackson believed that troops should withhold fire until they came to close quarters. In quoting the above authorities it must, however, be remembered that the reapons of their eras were in no sense arms of precision; hence to reserve fire would be almost essential to success.

Finally, Lord Roberts has reiterated the opinion that the battlo of the future is to be ron by skilful snap-shooting at close range, which seems to imply that the individual should be trained to deliver rapid and accurate fire at decisive range rather than spend time at acquiring accuracy of marksmanship at distances where hitting must, to a great extent, be a matter of chance.

There is no question, however, that to reserve fire entails a severe strain on the moral of troops-a strain which only soldiers of the best quality can bear.

The Training Manuals lay down certain rules regarding the opening of fire in attack, to which reference has been made; but in practice it would seem that the volume and accuracy of tho enemy's fire, and the conformation of the ground, will decide the question.

At the same time, instructive instances of the success of reserved fire by the attacker may be quoted from military history, such as Bunker's Hill, where the assailants were twice repulsed when fire was opened early, and were successful when it was reserved; the common practice of the Germans in '70 and the Russians in '77, necessitated by the inferior ranging power of their rifle; the action of the Boer left wing at Ingogo, which galloped to close quartors because the men "knew that they need only close to effective range, 
and their accurate fire would give them the victory"; the victory of the Allie: at Yang-Tsung over the Chinese in 1900.

Examples of the successful reservation of fire by the defender are:-Wolie's victory at Queboc; the rout of two French divisions by Sherbrooke's Division at Talavera; Ewell's action at Cross Keys in the Shenandoah Valley in 1862; Marye's Hill at Fredericksburg in the same year; the defence of Plevna by the Turks, and of the Shipka by the Russians in 1877; in the same war, Willelminofi's action at Sofia and Philippopolis; the action at Kaiping in the Chino-Japanese War of 1894 , where the Japanese were nearly beaten by this means; the action at Kailua in Tonkin in 1885; and lastly, the methods of the Boers at Thabanchu, Colenso, and Sand River. At 'Tacna, however, in the Chilian-Peruvian War of 1880 , the attempt of the latter, who were poor troops, to reserve frre resulted in a disaster.

In illustration of other means whereby superiority of firo is attained, certain hypothetical cases will be stated.

For example: If two forces, absolutely identical in every respect, meet on absolutely equal ground, and are both equally well led, neither side will gain fire superiority, except by pure accident.

If, however, other factors remain equal, but the Commander of one side so disposes or manouvres his troops that he can bring a greater number of rifles to bear on a portion of the enemy's line without weakening his own, he will establish superiority of fire at this point, and, by following up his advantage, may gain the victory:

For instance: A force on the defensive may arrange that a certain line of advance is swept by both frontal and flanking fire, or the assailant may employ the long range of his rifle to concentrate an overwhelming fire on a salient or may envelope a flank of the onemy's position. Napoleon is stated to have remarked that the art of fighting consisted in bringing this converging fire from every direction on a given point. In addition to assuring that, in the above cases, at the given point the volume of fire thus exceeds that of the adversary, a proportion of tho shots will be fired from a direction more or less oblique to the enemy's line, and the probability that they will bo effective will thereby be enhanced.

An historical example, or series of examples, of this principle may be cited from the Peninsular War, in which the British were victorious by dint of opposing the fire of the line to the shock of the column. It was the same at WTaterloo, as Wellington wrote: "The French came on in the same old way, and we beat them in the same old way."

Again, if tho two annies are equal in every other respect, except accuracy of fire, it is clear that the force which possesses this advantage will establish its superiority as soon as fire action takes placo at a range at which the individual qualities are decisive. This may be taken to bo about $\overline{5} 00$ yards.

With superior accuracy of fire, an inferior force has even at times defeated a superior, and it is claimed by De Wet that Nicholson's Nek is a case in point.

The same arguments may be applied to better control and direction of fire, to greater rapidity of fire; as demonstrated by Frederick the Great's early victories; his men wore so well trained that they could fire twice as fast as tho Austrians. It has, moreover, been found in a series of experiments that whereas with slow fire the 
percentage of hits to rounds is slightly better than with rapid, the number of hits obtained in a given time is double that of slow.

To supericrity of armament, such as the Prussians possessed in the war of 1866 (they could shoot lying down, whereas the Austrians had to stand up to load). To better use of cover, of which Majuba may be quoted as an instance. Majuba is also an example of skilful use of covering fire.

Other factors being equal, in two opposing forces the element of surprise often exercises a decisive effect in the struggle for fire superiority, and in this case a dense firing line should be used from the outset of the action. Surprise is perhaps more easily effected by the defender, as Magersfontein, and the experience of the 5 th Brigade at Colenso bear evidence. But Majuba aud the Rotherberg, at Spicheren, are instances when it materially assisted the assailant.

The last, and perhaps because it involves one of the other methods discussed, the most important, means by which fire superiority may be attained is the establishment of moral superiority, or, to call it by a simpler name, of confidence. It is not a constant factor, and may be present at one stage of a campaign or action and lacking at another.

It was said by Napoleon that in war the moral was to physical as 3 is to 1. And troops possess this moral superiority who are confident in their leaders, their armament, their power to make the best use of cover, and their marksmanship, and whose plysical powers are at their highest pitch.

An instance of moral superiority may be quoted in the combat of Echalar, in the battles of the Pyrenees, in 1813, where 1,500 British, elated by success and the personal daring of their General, drove a rearguard of 6,000 wearied and dispirited French from a very strong position. Thus, as Napier wrote:-_"The men who five days previously had assailed the terrible rocks of Sauroren with a courage that the hardiest British veterans could barely repel, were now unable to withstand the attack of one quarter of their numbers." But this was not all: "On the same day 80 marauding British soldiers, comrades, and equals of those who captured Echalar, surrendered to some unarmed French peasants, whom in ordinary circumstances," as Wellington said, "they could have eaten up."

Napier concludes by remarking: "What gross ignorance of human nature, then, do these declaimers display, who assert that the employing of brute force is the highest qualification of a General."

To sum up, therefore, fire superiority is attained, other factors being equal, by:-

1. Superiority of numbers.

2. Better leadership.

3. More modern armament.

4. Greater accuracy of fire, and if accuracy is not sacrificed, rapidity of fire.

5. More skilful use of cover.

6. Surprise.

7. Establishment of moral superiority. And judicious employment of covering fire is, for the assailant, an essential condition of success. 